\title{
Article
}

Mycosphere

\section{Functional variability of macrofungal populations in four different forest types of Costa Rica}

\author{
Rojas $\mathbf{C}^{1,2^{*}}$, Valverde $\mathbf{R}^{1}$ and Morales $\mathbf{R}^{3}$
}

\author{
${ }^{1}$ Engineering Research Institute, University of Costa Rica, San Pedro de Montes de Oca, 11501-Costa Rica. Emails: \\ carlos.rojasalvarado@ucr.ac.cr,nototriton@hotmail.com \\ ${ }^{2}$ Department of Biosystems Engineering, University of Costa Rica, San Pedro de Montes de Oca, 11501-Costa Rica \\ ${ }^{3}$ Department of Biology, Facultad Multidisciplinaria de Occidente, University of El Salvador, Santa Ana, El Salvador. \\ Email: quercusgigantea47@gmail.com
}

Rojas C, Valverde R, Morales R 2017 - Functional variability of macrofungal populations in four different forest types of Costa Rica. Mycosphere 8(9), 1288-1296, Doi 10.5943/mycosphere/8/9/3

\begin{abstract}
A series of functional variables, including biomass and hymenial area, were obtained for more than 4800 individual macrofungal sporocarps and correlated with a set of ecological parameters characterizing soil, climate and forest structure in four different forest types of Costa Rica. The idea behind this project was to document macrofungi over a three-year period with the objective of generating a dataset intended to document sporocarp variability and association with forest characteristics. In the context of climate change, habitat degradation and tropical forest fragmentation, studying fungi from an ecological perspective can provide crucial elements of analysis to weigh their relevance in tropical systems and to understand the potential threats to fungal populations. Our results showed high variability in the functional variables over the period of study, but suggest that such variability is partially induced by macroclimatic events in which forests with a higher percentage of mycorrhizal fungi seemed to be more sensitive. Overall, the ratio of hymenial area/biomass and pileus diameter were found to be significantly correlated with several ecological parameters in the studied forest types. However, the association of the former with ecological reproductive strategies makes such variable a good parameter to use for the monitoring of fungal dynamics in the studied tropical forests. The potential application of the latter in the framework of climate change and forest degradation studies is relevant since fungi are essential organisms in tropical ecosystems.
\end{abstract}

Key words - climate change - fungal ecology - monitoring - Neotropics - Tropical Dry Forest -

\section{Introduction}

In evolutionary biology, a functional character can be defined as a feature that performs an ecological function in a group of species with similar ecological demands (see Schwenk 2001). These characters are recognized to be evolutionarily stable (Dullemeijer 1980) since they represent key structural elements for ecological strategies within guilds. In macrofungi, structural elements of the sporocarp such as size dimensions, weight and reproductive area can be considered functional characters since they are expressions of the ecological strategies of fungi in the ecosystems 
inhabited by them. These characters are notable features commonly used for taxonomic purposes but their ecological relationships are still understudied.

Within a framework of a changing climate and strong external pressures over the different ecosystems where macrofungi are found, studies that can help determine associations between functional characters and ecosystem attributes are important and necessary. This is because such information can be used to design quick ecological assessments as proxies to document the effect of such global phenomena on fungal populations. In this sense, it is known that macrofungi can be used as indicators of forest health (Laganà et al. 2002), soil fertility (Kranabetter et al. 2009), environmental pollution (Kubrová \& Borovička 2015) and nature value (Marchetti 2004). Moreover, macrofungi have been documented to be affected by habitat loss (Halme et al. 2013), forest fragmentation (Nordén et al 2013) and climate change (Boddy et al. 2014; Hyde et al. 2016).

Despite such increasing evidence that macrofungi, as an ecological guild, can be used to determine ecosystem quality and changes in the ecological dynamics of biological systems, these types of studies are still not very common. As such, the documentation of the relationship between macrofungal dynamics and ecosystem quality in Neotropical areas, falls behind other types of research since studies in this part of the world are still strongly taxonomic in nature (e.g. AlvarezManjarrez et al. 2016, Sánchez-García et al. 2016). In Costa Rica for example, there have been few investigations with such focus (e.g. Carpenter et al. 2001, Desai et al. 2016) but the need has been established (see Rojas \& Doss 2014).

As a strategy to increase the documentation of the ecological role of macrofungi in Neotropical ecosystems, this study was designed and executed over a three-year period. The main objective was to generate baseline data on the relationship between fungal populations and habitat characteristics for future study design in the context of modern global phenomena. This investigation also recorded important characteristics of the studied forest systems that can be used to monitor forest dynamics over time. However, a different paper (Rojas \& Calvo 2014) focused on such forest-based complementary datasets.

\section{Materials \& Methods}

This project was carried out in Costa Rica during the 2012-2014 period in two selected sites on the Pacific side of the country. The first site was the Horizontes Experimental Forest Station (abbreviated hereafter as Horizontes), located in the Northwestern tropical moist climate zone of the Guanacaste province, and the second one was the Grecia Forest Reserve (abbreviated as Grecia), located in the central temperate wet climate zone of the Alajuela province (Figure 1). In both sites, two different forest types were selected based on the dominant tree species and within each of these systems, two 50x20 m plots were established and georeferenced. Forest patches of a) Hymenaea courbaril and b) Albizia saman were selected in Horizontes, whereas sections dominated by c) Cupressus lusitanica and d) Quercus seemannii were studied in Grecia. A complete forest characterization of carbon stocks and macrofungal diversity was the subject of a different analysis (see Rojas \& Calvo 2014) and the present contribution focuses on the functional dynamics of fungi in relation with ecosystem variables.

In each one of the two plots per forest type, a chemical characterization of soil, a forest characterization, a determination of canopy dynamics and a calculation of alfa-diversity of young plants were carried out during the period of study. For the soil, a series of 10 random samples were collected in each plot, pooled together and homogenized to use the Mehlich 3 protocol (Mehlich 1984) after which, chemical values for the principal elements were calculated. The forest characterization was performed as explained by Rojas \& Calvo (2014) and canopy height, tree volume, tree density and tree biomass were calculated using the allometric equation provided by Chou \& Gutiérrez-Espeleta (2012). For canopy dynamics, the hemispheric photography technique was used to determine canopy openness and leaf area index in each plot. The latter was carried out by calculating these variables three times a year during the dry season in March, the transitional period in June and the rainy season in October. Finally, the determination of young plant diversity 
was calculated by randomly establishing six internal $2 \times 2 \mathrm{~m}$ subplots in each experimental plot and counting/categorizing all seedlings/saplings within the $0.60-3 \mathrm{~m}$ vertical stratum. In addition, the temperature, atmospheric humidity and light intensity were measured with standard outdoor dataloggers in each plot for the entire period of study.

The sampling of macrofungi took place three times a year during the period between 20122014 in all plots. Sampling of fungi was carried out in a similar manner to the canopy assessment, during the dry, transitional and rainy periods. In this part of the study, each plot was carefully surveyed by three people and all visible macroscopic (larger than $1 \mathrm{~cm}$ tall) sporocarps of fungi were collected during each visit. Every individual sporocarp was identified, at least to genus level, and a series of functional measurements including pileus and stalk diameter, hymenial area and biomass were determined along with a ratio of the latter two. The biomass of each sporocarp was determined after transforming wet weight into dry weight using a curve obtained with a subset of samples. All records were categorized as mycorrhizal or saprobial according to their documented strategy of carbon uptake. The intuitive Simpson Index of Diversity (1-D) was calculated for the fungal component in both study sites and forest types and for the seedling/sapling assessment in each forest type.

After generating a three-year dataset, basic statistics were calculated for each forest type using all fungal and forest variables and significant differences were examined using ANOVAs after the determination of normality for each parameter. When differences were found, a post-hoc Tukey test was performed to determine the group responsible for differences. For further examination, multivariate statistics, including Principal Component Analysis (PCA) and Multiple Regression (MR) followed by the calculation of the Akaike Information Criterion (AIC) were used to determine the weight of the different parameters on the variability of the complete ecosystem-based dataset. Further correlations with the functional parameters were carried out with the first two principal components to evaluate degree of association. In all cases, the alpha value for testing the null hypothesis was 0.05 and all analyzes were carried out using the program JMP, version 10 .
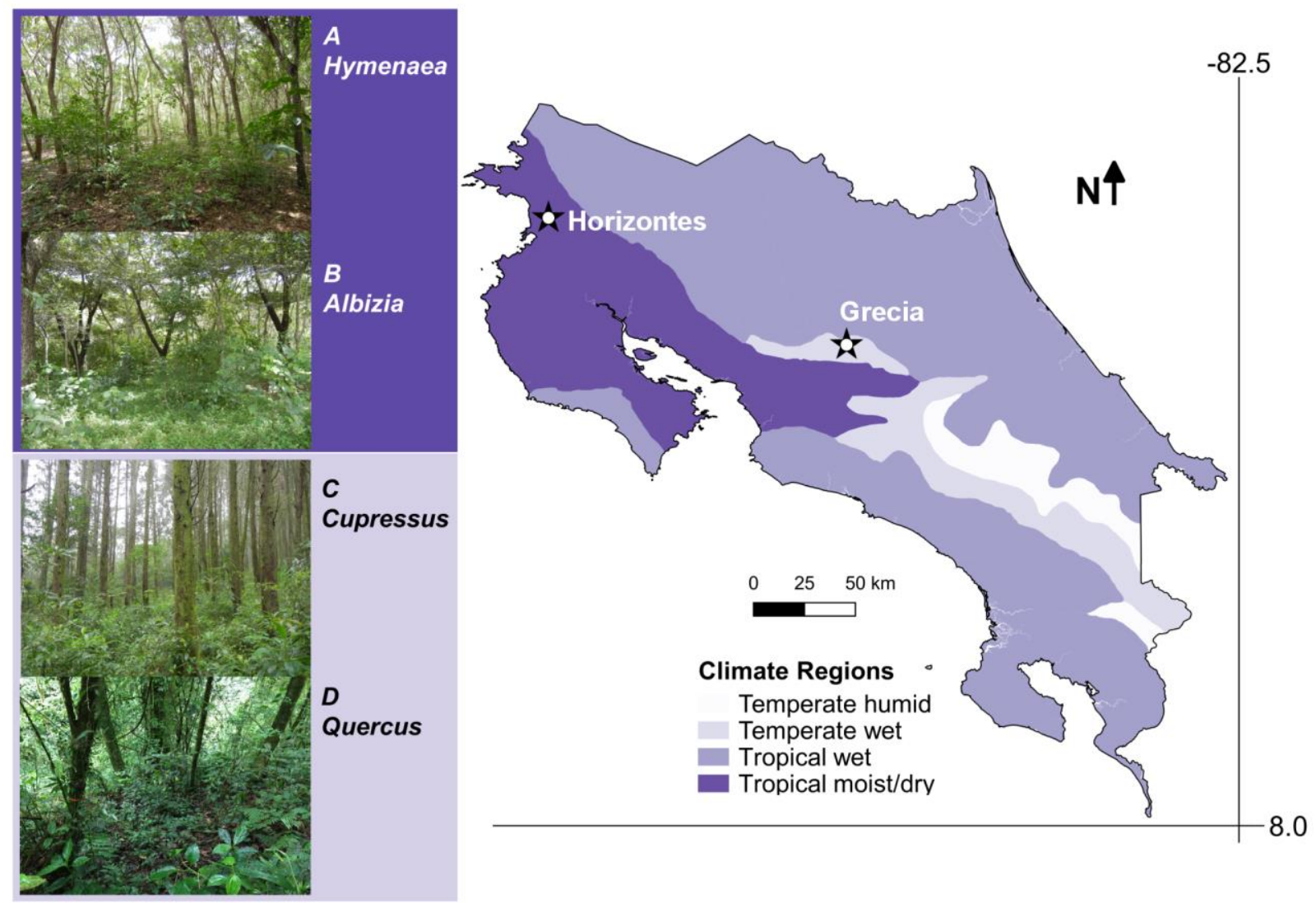

Figure 1 - Climate regions of Costa Rica showing the location of the studied sites. Forest types labeled A and B correspond to Horizontes, whereas C and D to Grecia. 


\section{Results}

A total of 4860 sporocarps of macrofungi were recorded and measured during this investigation. Out of that, about $65 \%$ were recorded in Horizontes and $35 \%$ in Grecia. In terms of years, $42 \%$ of all records were observed in 2014, 30\% in 2013 and 28\% in 2012. The forest type with the most records was the system dominated by $A$. saman with about $42 \%$ of the observations. This system was followed by the forests dominated by $Q$. seemannii and the ones dominated by $H$. courbaril, with about $29 \%$ and $22 \%$, respectively. The forest with $C$. lusitanica was the poorest one, in terms of records, with only $9 \%$ of all observations.

In general, macrofungi were larger in the dryer forests of Horizontes than in the moister forests of Grecia. However, the hymenial area was significantly larger in the latter (Table 1). Interestingly, when results are analyzed considering years, it seems that fungi were smaller in Grecia during 2012 and larger in Horizontes after the same year (Table 2). Overall, the $Q$. seemannii forest type yielded the macrofungi with the largest biomass and hymenial area, and the A. saman forest type yielded the most robust sporocarps (Table 3). The Simpson Index of Diversity was $0.956 \pm 0.04$ for Grecia and $0.815 \pm 1.3$ for Horizontes, whereas the same parameter for forest types was $0.948 \pm 0.03,0.926 \pm 0.07,0.909 \pm 0.04$ and $0.674 \pm 2.11$ for the systems dominated by $Q$. seemannii, $H$. courbaril, $C$. lusitanica and $A$. saman, respectively.

Table 1 Average values and standard deviation (in parentheses) for all functional variables determined in the present study, arranged by site, along with results of statistical analyses $(\mathrm{N}=4860)$.

\begin{tabular}{lccc}
\hline Functional variable & \multicolumn{2}{c}{ Site } & Result of t-test \\
& Grecia & Horizontes & Probability of no differences $(\boldsymbol{P})$ \\
\hline Average biomass $(\mathrm{g})$ & $1.13(0.04)$ & $0.31(0.03)$ & 0.0001 \\
Pileus diameter $(\mathrm{mm})$ & $3.20(0.31)$ & $12.38(0.25)$ & 0.0001 \\
Stalk diameter $(\mathrm{mm})$ & $1.08(0.18)$ & $2.91(0.15)$ & 0.0001 \\
Hymenial area $\left(\mathrm{mm}^{2}\right)$ & $10.89(0.32)$ & $6.87(0.31)$ & 0.0001 \\
HA/biomass $\left(\mathrm{mm}^{2} / \mathrm{g}\right)$ & $23.55(0.96)$ & $49.80(0.78)$ & 0.0001 \\
Saprobes $(\%$ of total) & 59 & 100 & 0.00003 \\
\hline
\end{tabular}

Of all the functional variables measured in the macrofungi studied, only pileus diameter and the ratio of hymenial area/biomass were highly correlated with forest or bioclimatic characteristics of the studied systems. The first one showed high positive correlation with light intensity $(\mathrm{r}=0.95)$, canopy openness $(\mathrm{r}=0.90)$ and negative correlations with leaf area index $(\mathrm{r}=-0.90)$, diversity of seedlings/saplings $(\mathrm{r}=-0.96)$, tree density $(\mathrm{r}=-0.91)$, tree biomass $(\mathrm{r}=-0.86)$ and tree volume $(\mathrm{r}=-$ $0.90)$. The ratio of hymenial area/biomass was positively correlated with temperature ( $\mathrm{r}=0.99)$, light intensity $(\mathrm{r}=0.94)$ and canopy openness $(\mathrm{r}=0.99)$; and negatively correlated with canopy height $(\mathrm{r}=-$ $0.89)$, tree volume ( $\mathrm{r}=-0.80)$, leaf area index $(\mathrm{r}=-0.99)$ and diversity of seedlings/saplings $(\mathrm{r}=-0.99)$. In relation to soil characteristics, pileus diameter was positively correlated with $\mathrm{Ca}^{+2}(\mathrm{r}=0.94)$ and Cation Exchange Capacity $\left(\mathrm{r}^{2}=0.91\right)$; whereas the ratio of hymenial area/biomass was positively correlated with $\mathrm{Ca}^{+2}(\mathrm{r}=0.97), \mathrm{Mg}^{+2}(\mathrm{r}=0.98), \mathrm{K}^{+}(\mathrm{r}=0.95)$ and Cation Exchange Capacity $\left(\mathrm{r}^{2}=0.99\right)$ and negatively correlated with water retention $(\mathrm{r}=-0.96)$ and percentage of clay $(\mathrm{r}=-0.99)$. Interestingly, the Simpson Index of Diversity was highly correlated with the quantity of phosphorus in the soil $(\mathrm{r}=0.99)$. Table 3 shows the general values of the soil and seedling/sapling characterization as well as the canopy assessment and the two functional macrofungal parameters with the most significance in this study. 
Table 2 Average values and standard deviation (in parentheses) for all functional variables determined in the present study, according with study site and year, along with results of statistical analyses $(\mathrm{N}=4860)$. Bold values represent the group responsible for differences in the Tukey tests when $\mathrm{P}<0.05$.

\begin{tabular}{|c|c|c|c|c|}
\hline \multirow{2}{*}{$\begin{array}{l}\text { Site } \\
\quad \text { Functional }\end{array}$} & \multicolumn{3}{|c|}{ Year } & \multirow{2}{*}{$\begin{array}{c}\text { Result of ANOVA/t-test } \\
\text { Probability of no differences (P) }\end{array}$} \\
\hline & 2012 & 2013 & 2014 & \\
\hline \multicolumn{5}{|l|}{ Horizontes } \\
\hline Average biomass (g) & $0.13(0.03)$ & $0.32(0.03)$ & $0.26(0.03)$ & 0.0012 \\
\hline Pileus diameter (mm) & $2.43(0.40)$ & $1.93(0.35)$ & $24.63(0.31)$ & 0.0001 \\
\hline Stalk diameter (mm) & $0.19(0.18)$ & $0.25(0.16)$ & $3.32(0.14)$ & 0.0001 \\
\hline Hymenial area $\left(\mathrm{mm}^{2}\right)$ & $5.52(0.35)$ & $4.97(0.31)$ & $4.72(0.29)$ & 0.2149 \\
\hline HA/biomass $\left(\mathrm{mm}^{2} / \mathrm{g}\right)$ & $53.77(1.55)$ & $38.08(1.35)$ & $54.25(1.25)$ & 0.0001 \\
\hline Saprobes (\% of total) & 100.0 & 100.0 & 100.0 & 0.0000 \\
\hline \multicolumn{5}{|l|}{ Grecia } \\
\hline Average biomass (g) & $0.56(0.15)$ & $2.07(0.18)$ & $1.71(0.13)$ & 0.0001 \\
\hline Pileus diameter (mm) & $2.41(0.11)$ & $3.72(0.13)$ & $3.60(0.09)$ & 0.0001 \\
\hline Stalk diameter (mm) & $0.40(0.03)$ & $0.97(0.04)$ & $0.66(0.03)$ & 0.0001 \\
\hline Hymenial area $\left(\mathrm{mm}^{2}\right)$ & $6.74(0.92)$ & $14.68(1.11)$ & $14.89(0.82)$ & 0.0001 \\
\hline HA/biomass $\left(\mathrm{mm}^{2} / \mathrm{g}\right)$ & $25.46(1.38)$ & $11.56(1.65)$ & $17.19(1.22)$ & 0.0001 \\
\hline Saprobes (\% of total) & 56.79 & 41.67 & 43.23 & 0.0001 \\
\hline
\end{tabular}

The PCA showed that about $99 \%$ of the variation in the ecosystem-based characterization was provided by canopy openness and phosphorus, a forest structural variable and a chemical soil parameter. A MR analysis followed by evaluation of AIC values confirmed the latter. The first principal component represented by canopy openness showed a high and significant $(P<0.05)$ correlation with the ratio of hymenial area/biomass $(\mathrm{r}=0.99)$ and a moderate correlation with the measurement of pileus diameter $(\mathrm{r}=0.77)$. In the last case, the correlation increased when the second principal component represented by level of phosphorus in the soil was included $(r=0.96$, not significant though).

\section{Discussion}

It is interesting to note that the dry forests of Horizontes were very productive during the time of the field surveys. Of course, the higher numbers of sporocarps and larger size of macrofungi reported herein are the byproduct of a series of conditions, including the moment where the surveys were carried out. However, these results showed that dry forests, albeit heavily seasonal in production of macrofungi, should not be neglected in research agendas on the relationship between tropical fungi and forests. An interesting result was that the largest percentage of records were associated with the A. saman forest type, a type of dry forest patch, since the leaves of this tree species are known to have antifungal properties (Suprapta \& Khalimi 2012). However, the most common genera in this forest type, shown in full in Rojas \& Calvo (2014) were Collybia and Marasmius, two macrofungal genera known to be generalists, whose productivity can thrive in adverse ecological conditions (Nordén et al. 2013) as a strategy to secure future colonization.

One aspect that should be pointed out, is that those results were also the product of a many records of Pseudofistulina radicata sporocarps in Horizontes during 2014, which skewed the measurements after 2012. However, it is still interesting that macrofungi were smaller in Grecia during 2012 and larger in Horizontes after the same year and that 2012 was the year with the lowest number of observations in both sites. Coinciding with our study, 2012 was reported to be the last year of a strong cold phase of ENSO, known as La Niña event (see Brenes \& Bonilla 2012), which 
increased the rainfall over the two studied sites. It is likely possible that the results presented herein were affected by this external climatic event in 2012 since forest performance is also modified by such phenomena (Martinez-Ramos et al. 2009). Interestingly, researchers have found, via soil respiration that increasing soil moisture has a negative effect of mycorrhizal activity (Heinemeyer et al. 2007) and thus, forests with a higher percentage of ectomycorrhizal fungi would likely be more affected by heavier rains. The results presented herein also support such observation, since Grecia showed more significant differences in macrofungal size than Horizontes, also suggesting that fungi in the former can be more susceptible than the latter to those events. As such, the role of external climatic events on the dynamics of the tree-fungi relationship would be an interesting topic to focus on for future research in tropical systems.

Table 3 Average values and standard deviation (in parentheses) for all functional variables determined in the present study according with forest type $(\mathrm{N}=4860)$ along with values for the ecosystem parameters measured in the canopy assessment, seedling characterization and soil analyses. All results of statistical analyses showed significant differences across groups and bold values represent the group responsible for differences in the Tukey test when $\mathrm{P}<0.05$.

\begin{tabular}{|c|c|c|c|c|}
\hline \multirow{2}{*}{$\begin{array}{l}\text { Functional variable } \\
\text { Ecosystem parameter }\end{array}$} & \multicolumn{4}{|c|}{ Forest Type } \\
\hline & C lusitanica & $Q$ seemannii & A. saman & H courbaril \\
\hline Average biomass (g) & $0.22(0.11)$ & $1.81(0.06)$ & $0.10(0.05)$ & $0.54(0.07)$ \\
\hline Pileus diameter (mm) & $1.90(0.64)$ & $3.68(0.37)$ & $8.73(0.29)$ & $16.61(0.40)$ \\
\hline Stalk diameter $(\mathrm{mm})$ & $0.50(0.21)$ & $0.70(0.12)$ & $0.84(0.09)$ & $2.79(0.13)$ \\
\hline Hymenial area (mm2) & $3.09(0.73)$ & $15.16(0.42)$ & $4.06(0.33)$ & $7.03(0.48)$ \\
\hline HA/biomass $\left(\mathrm{mm}^{2} / \mathrm{g}\right)$ & $18.02(1.98)$ & $18.87(1.15)$ & $48.99(0.90)$ & $48.51(1.30)$ \\
\hline Saprobes (\% of total) & 91.15 & 32.57 & 100 & 100 \\
\hline Canopy openness & $12.89(0.45)$ & $12.76(1.85)$ & $21.06(12.30)$ & $22.03(6.02)$ \\
\hline Leaf Area Index & $2.30(0.16)$ & $2.32(0.11)$ & $1.96(0.88)$ & $1.92(0.23)$ \\
\hline Seedling species $/ 4 \mathrm{~m}^{2}$ & $6.15(2.56)$ & $6.00(2.01)$ & $2.83(0.81)$ & $2.66(0.40)$ \\
\hline Seedling/sapling 1-D & $0.76(0.04)$ & $0.76(0.03)$ & $0.59(0.04)$ & $0.61(0.02)$ \\
\hline Percentage of clay in soil & $1.59(1.34)$ & $1.73(1.04)$ & $14.83(4.39)$ & $13.31(3.78)$ \\
\hline Water retention (ml/g soil) & $1.53(0.37)$ & $1.66(0.25)$ & $1.10(0.13)$ & $1.21(0.14)$ \\
\hline $\mathrm{Ca}^{+2}(\operatorname{cmol}[+] / \mathrm{L})$ & $3.10(0.69)$ & $2.98(1.17)$ & $12.05(0.06)$ & $10.83(1.17)$ \\
\hline $\mathrm{Mg}^{+2}(\mathrm{cmol}[+] / \mathrm{L})$ & $0.31(0.04)$ & $0.59(0.23)$ & $1.93(0.22)$ & $2.34(0.15)$ \\
\hline $\mathrm{K}^{+}(\mathrm{cmol}[+] / \mathrm{L})$ & $0.16(0.01)$ & $0.21(0.01)$ & $0.93(0.16)$ & $1.18(0.62)$ \\
\hline $\mathrm{P}(\mathrm{mg} / \mathrm{L})$ & $3.50(0.70)$ & $4.00(0.01)$ & $4.50(0.70)$ & $2.50(0.70)$ \\
\hline
\end{tabular}

When fungal diversity was analyzed, results showed a different but still expected pattern. Even though in terms of productivity and size of sporocarps, the forests of Horizontes yielded more individual and more robust sporocarps than the Grecia forests, it was the $Q$. seemannii forest type, with the largest component of ectomycorrhizal forms, the one with the highest diversity. This is not surprising since Neotropical oak forests have a high diversity of macrofungi (Mueller \& Halling 1995), but as it was observed in the results, this forest type also produced the sporocarps with the largest biomass and hymenial area. Since a significant percentage of species in this high elevation forest were ectomycorrhizal, the larger biomass in the fungi associated with this forest type may have simply be the product of such carbon uptake strategy, which does not limit sporocarp size as much as in the case of saprobes (see Corrêa et al. 2012). However, the implication of the largest 
hymenial area in the same forest types also reflect the long coevolutionary history between fungal and tree forms forming ectomycorrhizal associations (see Brundrett 2002).

The latter is also reflected in the fact that the hymenial area/biomass resulted in the functional parameter with the most forest type-based correlations. Given the strong evolutionary forces that have allowed fungal sporocarps to have the dimensions they do, an example of the evolutionary implications of the character paradigm (Schwenk 2001), the results shown herein seemed to be the product of functional specialization in the overall guild of species (e.g. $r=0.99$ for the significant correlation with canopy openness, meaning larger and lighter fungi in more open forest patches). In other words, it is possible that through the measurement of the hymenial area/biomass character, results could have shown a distinctive ecological "label" reflecting characteristics of the forest (lower than $20 \mathrm{~mm}^{2} / \mathrm{g}$ for the temperate wet Grecia forests and higher than $45 \mathrm{~mm}^{2} / \mathrm{g}$ for tropical moist/dry Horizontes forests) as well as ecological strategies of the fungal guilds associated with them. If that was the case, the application of a characterization of hymenial area/biomass in future ecological studies could be useful for monitoring of fungal productivity and overall health of fungal populations (e.g. $r=-0.96$ for the correlation with water retention in soils, which as expected, was higher in the ectomycorrhizal forests of Grecia) in forest systems like the ones studied in the present investigation.

The other functional variable that showed to be correlated with many characteristics of the forest systems studied was pileus diameter. Interestingly, this character has been reported to be an adequate morphological feature, matching molecular data, for identification of a group of species of Cortinarius (see Peintner 2008). Similarly, other researchers found the character to be an adequate predictor of spore yield in a species of Ganoderma (Fu et al. 2013). However, from an ecological perspective it seems that pileus size is related with spore dispersal efficiency (Dressaire et al. 2016). These researchers showed that it is through the use of convective currents formed by thermal differentials, initially formed by rapid water loss associated with spore dispersal, that some species of mushrooms disperse their spores. In this sense, the results of the present study (e.g. $r=0.90$ for the correlation between pileus size and canopy openness, a forest character that increases temperature in the understory) seem to support the idea that pileus size is a functional character with ecological implications in macrofungal populations dynamics.

Finally, the fact that phosphorus was found to be significant to explain the variability in the dataset generated in the present study, is not surprising either, given the importance of such element in the context of forest dynamics (see Manzoni et al. 2010). However, it is very remarkable that such parameter was found to be the second most important variable, and it was important to generate a strong multiple correlation with pileus diameter. It has been observed that phosphorus does not influence diversity or productivity of ectomycorrhizal macrofungi (Falkengren-Grerup et al. 1994) but it seems to affect diversity of saprobes (Harrington 2003). In this sense, for the present investigation, the phosphorus-pileus diameter relationship may be explained by the differences in the percentage of saprobes across forest types and sites. The implication of the latter is that the studied forest types truly have a cascade of differences explaining the functional variability of macrofungi, which are reflected ecologically in the different guilds of species present in the different locations.

In the framework of climate change and forest degradation, studies like the one presented herein are relevant due the role that fungi play in the dynamics of tropical forests. However, the lack of studies in tropical areas, makes it difficult to establish comparisons between the results found in this investigation and similar ones also in tropical forest systems. Despite the latter, it is imperative to generate baseline data to understand that tropical fungi, from an ecological point of view, rely on a balance of ecological and evolutionary relationships with the environments they inhabit. This study has generated valuable information associated with four forest types in Costa Rica, but it has also provided some insights in the potential application of functional characterization of macrofungi for monitoring purposes. 


\section{Acknowledgements}

This work was financed by the University of Costa Rica through research projects 731-B2222, 731-B5-059 and activity 731-A0-826. Appreciation is extended to Jennifer Ramirez, Pedro Rojas, Erick Calvo, Philippe Clerc, Gabriela Loza and Stephanie Somerville for their help in the field. We would also like to acknowledge the support of the Horizontes Experimental Forest Station and the Grecia Forest Reserve during the study by granting us permission to work in the forests located in these areas.

\section{References}

Alvarez-Manjarrez J, Villegas-Ríos M, Garibay-Orijel R, Contreras-Pacheco M, Kõljalg U. 2016 Tomentella brunneoincrustata, the first described species of the Pisonieae-associated Neotropical Tomentella clade, and phylogenetic analysis of the genus in Mexico. Mycological Progress 15, 10.

Boddy L, Büntgen U, Egli S, Gange AC, et al. 2014 - Climate variation effects on fungal fruiting, Fungal Ecology 10, 20-33.

Bonilla A, Brenes A. 2012 - La Niña 2010-2012. Estudio de caso Costa Rica. Global Assessment Report on Disaster Risk Reduction GAR 2013. UNISDR, Cali.

Brundrett MC. 2002 - Coevolution of roots and mycorrhizas of land plants. New Phytologist 154, 275-304.

Carpenter FL, Palacios Mayorga S, Gonzalez Quintero E, Schroeder M. 2001 - Land-use and erosion of a Costa Rican Ultisol affect soil chemistry, mycorrhizal fungi and early regeneration. Forest Ecology and Management 144, 1-17.

Chou SW, Gutiérrez-Espeleta E. 2012 - Ecuación para estimar la biomasa arbórea en los bosques tropicales de Costa Rica. Tecnología en Marcha 26, 41-54.

Corrêa A, Gurevitch J, Martins-Loução MA, Cruz C. 2012 - C allocation to the fungus is not a cost to the plant in ectomycorrhizae. Oikos 121, 449-463.

Christensen M, Heiiman-Clausen J, Walleyin R, Adamcik S. 2004 - Wood inhabiting fungi as indicators of nature value in european beech forests. In: Marchetti M. (ed) Monitoring and Indicators of Forest Biodiversity in Europe: from ideas to operationality. EFI Procedings 51, Joensuu, Finland. pp 229-238.

Desai NS, Wilson AW, Powers JS, Mueller GM, Egerton-Warburton LM. 2016 - Ectomycorrhizal diversity and community structure in stands of Quercus oleoides in the seasonally dry tropical forests of Costa Rica. Environmental Research Letters, 125007.

Dressaire E, Yamada L, Song B, Roper M. 2016 - Mushrooms use convectively created airflows todisperse their spores. PNAS 113, 2833-2838.

Dullemeijer P. 1980 - Functional morphology and evolutionary biology. Acta Biotheoretica 29, $151-250$.

Falkengren-Grerup U, Rühling Å, Tyler G. 1994 - Effects of phosphorus application on vascular plants and macrofungi in an acid beech forest soil. Science of The Total Environment 151, 125-130.

$\mathrm{Fu} \mathrm{L}$, Cheng J, Li H, Wei H, et al. 2013 - Association of various fruiting body macromorphological traits with spore yield in Ganoderma Lingzhi (higher Basidiomycetes), a new medicinal mushroom from China. International Journal of Medicinal Mushrooms 15, 91-99.

Halmem P, Ódor P, Christensen M, Piltaver A et al. 2013 - The effects of habitat degradation on metacommunity structure of wood-inhabiting fungi in European beech forests. Biological Conservation 168, 24-30.

Harrington TJ. 2003 - Relationships between macrofungi and vegetation in the Burren. Biology and Environment: Proceedings of the Royal Irish Academy 103B, 147-159.

Heinemeyer A, Hartley IP, Evans SP, Carreira de la Fuente JA, Ineson P. 2007 - Forest soil $\mathrm{CO}_{2}$ flux: uncovering the contribution and environmental responses of ectomycorrhizas. Global Change Biology 13, 1786-1797. 
Hyde KD, Fryar S, Tian Q, Bahkali AH et al. 2016 - Lignicolous freshwater fungi along a northsouth latitudinal gradient in the Asian/Australian region; can we predict the impact of global warming on biodiversity and function? Fungal Ecology 19, 191-201.

Kranabetter JM, Friesen J, Gamiet S, Kroeger P. 2009 - Epigeous fruiting bodies of ectomycorrhizal fungi as indicators of soil fertility and associated nitrogen status of boreal forests. Mycorrhiza 19, 535-548.

Kubrová J, Borovička J. 2015 - Do macrofungi accumulate uranium? In: Merkel B, Arab A. (eds) Uranium - Past and Future Challenges. Springer, Cham. pp. 369-376.

Laganà A, Salerni E, Barluzzi C, Perini C et al. 2002 - Macrofungi as long-term indicators of forest health and management in Central Italy. Cryptogamie Mycologie 23, 3-50.

Manzoni S, Trofymow JA, Jackson RB, Porporato A. 2010 - Stoichiometric controls on carbon, nitrogen, and phosphorus dynamics in decomposing litter. Ecological Monographs 80, 89106.

Martínez-Ramos M, Anten NPR, Ackerly DD. 2009 - Defoliation and ENSO effects on vital rates of an understorey tropical rain forest palm. Journal of Ecology 97, 1050-1061.

Mehlich A. 1984 - Mehlich 3 Soil Test Extractant: A Modification of Mehlich 2 Extractant. Communications in Soil Science and Plant Analysis 15, 277-294.

Mueller GM, Halling RE. 1995. Evidence for high diversity of Agaricales (Fungi) in Neotropical Montane Quercus forests. In: Churchill SP, Balslev H, Forrero E, Luteyn JL. (eds.) Biodiversity and Conservation of Neotropical Montane Forests: NYBG, New York. pp 303312.

Nordén J, Penttilä R, Siitonen J, Tomppo E et al. 2013 - Specialist species of wood-inhabiting fungi struggle while generalists thrive in fragmented boreal forests. Journal of Ecology 101, 701-712.

Peintner U. 2008 - Cortinarius alpinus as an example for morphological and phylogenetic species concepts in ectomycorrhizal fungi. Sommerfeltia 31, 161-177.

Rojas C, Calvo E. 2014 - Forest biomass, carbon stocks and macrofungal dynamics: a study case in Costa Rica. International Journal of Forestry Research Doi, Article ID 607372, 6 pages.

Rojas C, Doss RG. 2014 - Carbono, bosques y micorrizas: una "negación de investigación imperativa". Brenesia 81-82, 91-95.

Sánchez-García M, Henkel TW, Aime MC, Smith ME et al. 2016 - Guyanagarika, a new ectomycorrhizal genus of Agaricales from the Neotropics. Fungal Biology 120, 1540-1553.

Schwenk K. 2001 - Functional units and their evolution. In: Wagner G. (ed.) The character concept in evolutionary biology. Academic Press, Massachusetts. pp 165-198.

Suprapta DN, Khalimi K. 2012 - Anti-fungal activities of selected tropical plants from Bali Island. Phytopharmacology 2, 265-270. 